\title{
Management of respiratory failure due to covid-19
}

\author{
Pathology and management are similar to acute respiratory distress syndrome
}

\author{
Susan R Wilcox chief \\ Division of Critical Care, Department of Emergency Medicine, Massachusetts General Hospital, Harvard Medical School, Boston, MA, USA
}

The most concerning complication of SARS-CoV-2 infection (covid-19) is acute hypoxaemic respiratory failure requiring mechanical ventilation. Numerous mechanisms have been suggested for the substantial hypoxaemia seen in many patients. ${ }^{1}$ These include pulmonary oedema, haemoglobinopathies, vascular occlusion, and a mismatch between ventilation and perfusion.

The available histopathology, however, shows diffuse alveolar damage $^{2}$ consistent with acute respiratory distress syndrome (ARDS). Several of the other suggested aetiologies are also consistent with ARDS, and microvascular and macrovascular thrombi in ARDS have been recognised for decades. ${ }^{3}$ The variable pulmonary compliance associated with severe covid-19 is comparable with pulmonary compliance values reported for ARDS. $^{45}$ The heterogeneity of ARDS is well documented, with distinct subtypes related to the degree of inflammation and response to positive end expiratory pressure (PEEP). ${ }^{56}$ Overall, the pathology seen in patients with covid-19 is very similar to established descriptions of ARDS.

\section{Oxygen therapy}

The trivial dyspnoea experienced by some patients with demonstrable hypoxaemia has led to debates about the need for oxygen therapy. However, hypoxaemia is a poor stimulus for dyspnoea, and variation in symptoms associated with hypoxaemia is unsurprising. Even for patients with minimal symptoms, available evidence does not support tolerating hypoxaemia. A recent randomised trial comparing liberal (target oxygen saturation $\geq 96 \%$ ) and conservative (target 88-92\%) strategies for oxygen therapy in patients with ARDS was stopped early after it became clear that the conservative approach was unlikely to benefit patients and might cause harm. ${ }^{7}$ Recent guidance recommends a target oxygen saturation of $92-96 \%$ in adults with covid-19, using supplemental oxygen as needed. ${ }^{8}$

Some patients will require support beyond supplemental oxygen, and the choice between high flow nasal cannula, non-invasive positive pressure ventilation, or early intubation has been controversial. Issues include the need to protect healthcare workers from exposure to viral aerosols while providing optimal care for patients.
Oxygen delivered through high flow nasal cannulas is beneficial in hypoxaemic respiratory failure ${ }^{9}$ and can provide up to 60 $\mathrm{L} /$ min of nearly $100 \%$ oxygen. The risk of virus aerosols from this delivery method is probably low, ${ }^{10}$ although concerns remain. Patient selection is critical; those with moderate to severe hypoxaemia are unlikely to get enough oxygen through high flow nasal cannulas and will usually require intubation. ${ }^{11}$ Stable patients with isolated mild to moderate hypoxaemia can be given oxygen through nasal cannulas but should be monitored carefully for signs of deterioration.

\section{Non-invasive ventilation}

Non-invasive positive pressure ventilation (NIPPV) provides ventilatory support without the need for an endotracheal airway, so patients remain awake. While this option is non-invasive it isn't completely benign. Patients retain some control over their breathing and large volume breaths can cause self-inflicted lung injury, ${ }^{12}$ which has been associated with higher mortality among patients subsequently admitted to an intensive care unit with ARDS ${ }^{13}$ In one small retrospective case series from Wuhan, $72 \%$ of covid-19 patients given NIPPV died, although death rates were also high for patients intubated from the outset. ${ }^{14}$ NIPPV is associated with a variable and hard to quantify risk of aerosol generation, which may depend on the tightness of the seal around a patient's mask. ${ }^{15}$ Given the unclear benefit to patients, non-invasive ventilation is probably of limited value in patients with hypoxaemic respiratory failure due to covid-19. ${ }^{15}$ Uncertainty about how best to optimise respiratory support has led to increased use of prone positioning for patients who are not intubated (awake proning). Lying prone improves ventilation-perfusion matching and is associated with reduced mortality among patients with ARDS, when compared with supine positioning. ${ }^{4}$ Observational evidence from patients with viral ARDS and with covid-19 ${ }^{16}{ }^{17}$ provides reasonable support for a trial of awake proning in selected patients, particularly as it is a low risk intervention.

\section{Intubation}

Arguments for and against early intubation are not yet resolved, largely because good evidence is lacking. Those who 
recommend prompt intubation suggest that it avoids the risk of self-induced lung injury. ${ }^{18}$ Those who argue against early intubation note the high death rates reported among intubated patients with covid-19 and cite concerns that ventilator induced lung injury is a contributing factor. The best approach will likely vary by patient. A single approach is unlikely to work in a disease as heterogeneous as covid-19.

Since ARDS caused by covid-19 is similar to ARDS with other causes, the principles underpinning ventilation should also be similar: provide ventilation to protect the lungs with low tidal volumes, low driving pressures, and titration of positive end expiratory pressure to meet each patient's needs, with the overall goal of improving lung compliance.

Substantial evidence shows that protective ventilation with lower tidal volumes and pressures is strongly associated with improved outcomes in patients with ARDS. ${ }^{19}$ Patients who remain hypoxaemic despite optimal ventilation should be considered for prone positioning while intubated. ${ }^{4}$

Data may be scarce, but we have enough to support evidence based management of covid-19- from optimising oxygenation, providing respiratory support, intubating when necessary, and tailoring ventilatory pressure to patients' specific needs.

Competing interests: The $B M J$ has judged that there are no disqualifying financial ties to commercial companies. The author declares the following other interests: Expert witness for legal firm for defence, travel expenses and honorariums from a non-commercial professional society for presentations on mechanical ventilation. The BMJ policy on financial interests is here: https://www.bmj.com/sites/default/ files/attachments/resources/2016/03/16-current-bmj-education-coi-form.pdf. Provenance and peer review: Commissioned; not externally peer reviewed.

1 Wang D, Hu B, Hu C, etal . Clinical characteristics of 138 hospitalized patients with 2019 novel coronavirus-infected pneumonia in Wuhan, China. JAMA 2020;323:1061-9. 10.1001/jama.2020.1585 32031570

2 Tian S, Hu W, Niu L, Liu H, Xu H, Xiao S-Y. Pulmonary pathology of early-phase 2019 novel coronavirus (COVID-19) pneumonia in two patients withlLung cancer. $J$ Thorac Oncol 2020;15:700-4. 10.1016/j.jtho.2020.02.010 32114094

3 Tomashefski JFJr, Davies P, Boggis C, Greene R, Zapol WM, Reid LM. The pulmonary vascular lesions of the adult respiratory distress syndrome. Am J Pathol 1983;112:112-26.6859225
4 Guérin C, Reignier J, Richard J-C, etal. PROSEVA Study Group. Prone positioning in severe acute respiratory distress syndrome. N Engl J Med 2013;368:2159-68. 10.1056/NEJMoa1214103 23688302

5 Gattinoni L, Caironi P, Cressoni M, etal . Lung recruitment in patients with the acute respiratory distress syndrome. N Engl J Med 2006;354:1775-86. 10.1056/NEJMoa052052 16641394

6 Calfee CS, Delucchi K, Parsons PE, Thompson BT, Ware LB, Matthay MANHLBI ARDS Network. Subphenotypes in acute respiratory distress syndrome: latent class analysis of data from two randomised controlled trials. Lancet Respir Med 2014;2:611-20. 10.1016/S2213-2600(14)70097-9 24853585

7 Barrot L, Asfar P, Mauny F, etal. LOCO2 Investigators and REVA Research Network. Liberal or conservative oxygen therapy for acute respiratory distress syndrome. $N$ Engl J Med 2020;382:999-1008. 10.1056/NEJMoa1916431 32160661

8 Alhazzani W, Møller MH, Arabi YM, etal . Surviving sepsis campaign: guidelines on the management of critically ill adults with coronavirus disease 2019 (COVID-19). Intensive Care Med 2020:1-34. [Epub ahead of print.]322222812

9 Frat JP, Thille AW, Mercat A, etal. FLORALI Study GroupREVA Network. High-flow oxygen through nasal cannula in acute hypoxemic respiratory failure. $N$ Engl $\mathrm{J} \mathrm{Med}$ 2015;372:2185-96. 10.1056/NEJMoa1503326 25981908

10 Hui DS, Chow BK, Lo T, etal . Exhaled air dispersion during high-flow nasal cannula therapy versus CPAP via different masks. Eur Respir J 2019;53:1802339. 10.1183/13993003.02339-2018 30705129

11 Rello J, Pérez M, Roca O, etal. CRIPS investigators. High-flow nasal therapy in adults with severe acute respiratory infection: a cohort study in patients with 2009 influenza A/H1N1v. J Crit Care 2012;27:434-9. 10.1016/j.jcrc.2012.04.006 22762937

12 Brochard L, Slutsky A, Pesenti A. Mechanical ventilation to minimize progression of lung injury in acute respiratory failure. Am J Respir Crit Care Med 2017;195:438-42. 10.1164/rccm.201605-1081CP 27626833

13 Bellani G, Laffey JG, Pham T, etal. LUNG SAFE InvestigatorsESICM Trials Group. Noninvasive ventilation of patients with acute respiratory distress syndrome. Insights from the LUNG SAFE Study. Am J Respir Crit Care Med 2017;195:67-77. 10.1164/rccm.201606-1306OC 27753501

14 Yang $X, Y u Y, X u$ J, etal . Clinical course and outcomes of critically ill patients with SARS-CoV-2 pneumonia in Wuhan, China: a single-centered, retrospective, observational study. Lancet Respir Med 2020;S2213-2600(20)30079-5. 10.1016/S2213-2600(20)30079-510.1016/S2213-2600(20)30079-5 32105632

15 Wax RS, Christian MD. Practical recommendations for critical care and anesthesiology teams caring for novel coronavirus (2019-nCoV) patients. Canadian Journal of Anesthesia. Springer, 2020.

16 Ding L, Wang L, Ma W, He H. Efficacy and safety of early prone positioning combined with HFNC or NIV in moderate to severe ARDS: a multi-center prospective cohort study. Crit Care 2020;24:28. 10.1186/s13054-020-2738-5 32000806

17 Caputo ND, Strayer RJ, Levitan R. Early self-proning in awake, non-intubated patients in the emergency department: a single ED's experience during the covid-19 pandemic. Acad Emerg Med 2020. 10.1111/acem.13994 32320506

18 Gattinoni L, Coppola S, Cressoni M, Busana M, Rossi S, Chiumello D. Covid-19 does not lead to a "typical" acute respiratory distress syndrome. Am J Respir Crit Care Med 2020. 10.1164/rccm.202003-0817LE 32228035

19 Fan E, Brodie D, Slutsky AS. Acute respiratory distress syndrome: advances in diagnosis and treatment. JAMA 2018;319:698-710. 10.1001/jama.2017.21907 29466596

20 Bhatraju PK, Ghassemieh BJ, Nichols M, etal . Covid-19 in critically ill patients in the Seattle region - case series. N Engl J Med 2020. 10.1056/NEJMoa2004500 32227758

Published by the BMJ Publishing Group Limited. For permission to use (where not already granted under a licence) please go to http://group.bmj.com/group/rights-licensing/ permissions 